Forthcoming in Synthese

(Special Issue on Objectivity in Science, eds. Matteo Colombo, Mark Colyvan, Raoul Gervais, Paul Griffiths, Stephan Hartmann and Jan Sprenger)

\title{
How Objective Are Biological Functions?
}

\author{
Marcel Weber \\ marcel.weber@unige.ch
}

\begin{abstract}
John Searle has argued that functions owe their existence to the value that we put into life and survival. In this paper, I will provide a critique of Searle's argument concerning the ontology of functions. I rely on a standard analysis of functional predicates as relating not only a biological entity (e.g., the heart), an activity that constitutes the function of this entity (e.g., pumping blood) and a type of system but also a goal state (e.g., survival or evolutionary fitness). A functional attribution without specification of such a goal state has no truth-value. But if completed with a goal state, functional attributions understood as four-place relations attain a truth-value. The truth conditions of all attributions of function involve a dependence claim of the goal state on the function bearer's activity. The nature of this dependence may differ; I consider five different possibilities: causality, mechanistic constitution, mereology, supervenience and metaphysical grounding. If these dependency relations are objective, Searle's central ontological thesis fails. What he ought to have said is that our valuing survival or other goal states may be the reason why biology seeks functional knowledge, but this has nothing to do with ontology. I will show further that Searle also raised an interesting challenge concerning the relationship of functional and causal truths, but it does not threaten the
\end{abstract}


objectivity of functions either. At best, it could show that functional vocabulary is eliminable. However, I will show that functional vocabulary is not so eliminable.

\section{Keywords}

Biological functions; objectivity; ontology; causality; supervenience; mereology; mechanistic constitution; grounding; eliminability 


\section{Introduction}

Biological functions have always been shady citizens of the objective world. There is a long tradition in thinking that functional statements about biological systems should not considered to be objectively true because they represent some kind of natural purposes or teleology. The most famous philosophical work defending such a view, of course, is Kant's Critique of Teleological Judgment (1913). More recently, the objectivity of functions has been challenged by John Searle (1995). The gist of Searle's argument is that a functional account of some biological organ or structure does not add anything to a description of the causal relations in which this organ or structure stands, except some kind of evaluation. On his view, it is because we value life and survival that we try to describe biological systems functionally. Thus, without our evaluations, the world would contain only causal relations, but no biological functions. Here is Searle's argument in full:

[T]he discovery of a natural function can take place only within a set of prior assignments of value (including purposes, teleology, and other functions). Thus given that we already accept that for organisms there is a value in survival and reproduction, and that for species there is a value in continued existence, we can discover that the function of the heart is to pump blood [...]. When we discover such a natural function, there are no natural facts discovered beyond the causal facts. Part of what the vocabulary of 'functions' adds to the vocabulary of 'causes' is a set of values (including purposes and teleology generally). It is because we take it for granted in biology that life and survival are values that we can discover that the function of the heart is to pump blood. If we thought the most important value in the world was to glorify God by making thumping noises, then the function of the heart would be to make thumping noise, 
and the noisier heart would be the better heart. If we valued death and extinction above all, then we would say that the function of cancer is to speed death (Searle 1995, 15).

What Searle is trying to establish in this passage, I contend, is the following: He defends some kind of (1) a thesis of ontological dependence of functions on values. As he takes values to be subjective, it follows that functions are subjective. (2) Searle holds some kind of eliminativism about biological functions. His claim that there are no natural facts beyond the causal facts to be discovered in biology means that functional facts are not natural facts. ${ }^{1}$ The reason is their ontological dependence on values, which Searle takes to be mind-dependent. The mind-dependence of values is controversial, of course, but I shall not enter into this debate and grant him this premise. Functional statements may imply causal statements such as "contractions of the heart muscle cause blood circulation" and these causal statements are perfectly natural (i.e., objective). But with respect to the purpose of discovering natural facts, functional terms are fully eliminable according to Searle. ${ }^{2}$

\footnotetext{
${ }^{1}$ I assume that the term "natural function" is used by Searle in order to mark a contrast to artificial or technical function, as his position clearly implies that biological functions are not natural.

${ }^{2}$ To my knowledge, Searle's views on this matter have not previously been discussed in the philosophy of biology. However, they have been cited with approval by other philosophers (e.g., Kusch 2006) and the argument is systematically interesting. Furthermore, similar positions have also been defended by philosophers of biology (e.g., Ratcliffe 2000).
} 
I think the two theses (1) and (2) should be treated separately. For whether or not functions add anything to the causal facts is a different question from whether functions are objective. I think it is easy to see that even if functions were just causes, this would not mean that they are not real (provided that causes are real).

Obviously, whether or not Searle's claims with respect to functions are true will depend on what exactly the term "function" is taken to mean. Searle does not specify. Should we assume that he means "function" in some ordinary language sense, in a sense used by scientists or in some philosophically reconstructed sense? The text gives no indications one way or the other, therefore his thesis is difficult to evaluate in the form it is stated. In this paper, I will not be concerned with any pre-theoretical sense of "function" but with philosophically reconstructed conceptions. My main purpose here is to examine to what extent Searle's claims about functions are borne out by such reconstructions.

Here is my plan for this endeavor. In Section 2, I present a meta-analysis of function predicates that generalizes some of the most influential analyses of function that have been proposed, in particular the causal role, dispositional and etiological functions. In Section 3, I show that functions are ontologically objective using the account from Section 2. In Section 4, I strengthen my argument by investigating further the core meaning of function predicates with these questions in mind. I argue that what makes a function statement true is either a causal dependence, a part-whole relation, a relation of mechanistic constitution or a metaphysical grounding relation. All of these relations are normally considered to be objective. If this is correct, Searle's ontological claim about value-dependence falls. Section 5 then takes up Searle's eliminativist thesis, i.e., challenge of saying what functional vocabulary adds to the causal description of the inner workings of an organism. It will turn out that specific functional attributions may indeed reduce to causal, constitutive, mereological, or grounding relations. There may not be anything that all functional dependence relations have in common 
qua functional relations. However, this does not mean functions are unreal or eliminable. As I will argue, something similar as Searle says about functions can be said about causal truths themselves, and few people think that causal vocabulary is eliminable. In Section 6, I consider an objection according to which such an account as I defend leaves us with far too many functions. Finally, in Section 7 I draw together the different strands of argument presented.

\section{A Meta-Analysis of Functions as (at Least) Quaternary Relations}

Obviously, answering the question about the objectivity of functions requires some assumptions as to what exactly a biological function is. There exist many attempts to elaborate and defend an account of biological functions, most of which try to somehow "naturalize" functions (e.g., Hempel 1959; Nagel 1961; Wright 1973; Cummins 1975; Boorse 1977; Bigelow and Pargetter 1987; Millikan 1989; Neander 1991; Griffiths 1993; Godfrey Smith 1994; McLaughlin 2001; Mossio, Saborido, and Moreno 2009; Kingma 2016; to name just a few. See Garson 2016 for a recent overview of the debate).

Some of these approaches could be used to confront Searle's challenge head on. For example, according to the proper functions account (Millikan 1989, Neander 1991), functions will be objective to the extent in which the relevant selection history that grounds functional attributions is an objective feature of organisms. Similarly, proponents of the organizational account of functions (Mossio, Saborido and Moreno 2009) take biological systems to exhibit a teleological organization not shown by non-living natural systems (for a critique of this view see Garson 2016, Ch. 6). This teleological organization is considered to be an objective feature of living organisms, thus Searle's claims about functions are directly opposed. ${ }^{3}$

I will take a different route in this paper. I will focus on what is known as the "dispositional" analysis of functions, the most influential version of which is Cummins (1975). I have

\footnotetext{
${ }^{3}$ I wish to thank an anonymous referee for pointing this out.
} 
defended an enriched version of this account elsewhere (Weber 2005). This account does not postulate any strong kind of teleology ${ }^{4}$ and it may therefore seem unsurprising if functions come out as objective under it. However, it should be noted that the dispositional account has been considered to be "interest-relative" since its inception and if this is correct, Searle's point stands. It will thus be necessary to somehow deal with this alleged interest-relativity if Searle's thesis is to be refuted.

I also contend that the dispositional account is able to accommodate some of the other analyses that have been proposed, as I will show below. However, there are clearly accounts of function that do not fit the dispositional analysis, for instance, the organizational account mentioned. ${ }^{5}$

The essence of the dispositional account may be captured by the following abstract structure:

$\mathrm{F}(\mathrm{X}, \mathrm{G}, \mathrm{S}, \varphi)$ : X's function with respect to goal state $\mathrm{G}$ in system $\mathrm{S}$ is to $\varphi$ In such a predicate, $\mathrm{X}$ designates some biological structure or organ, some thing which can be said to have a function. X can also be a behavior (e.g., the famous dance of the honeybees), a process (e.g., glycolysis) or an internal state (e.g., a perceptive state or a sensation such as

\footnotetext{
${ }^{4}$ By this I mean in particular a kind of teleology that includes a normative dimension. I do not believe that there is any kind of normativity involved in biological functions beyond the simple fact that functional dispositions may fail to be manifested. However, I lack the space here to deal with this issue appropriately.

${ }^{5}$ Another functional concept that doesn't fit the analysis that I am about to present is Wouters' (2003) concept of function as activity.
} 
hunger). ${ }^{6} \mathrm{G}$ designates a goal state, about which I will say more below. S is a biological system that contains X. It can be a whole organism or a part of an organism, for example, a subsystem such as the cardiovascular system. Finally, $\varphi$ is some activity that $\mathrm{X}$ is capable of performing. Before I discuss the implications of this analysis for he problem at hand, some remarks are in order.

First, this construal of functions is quite common (cf. Wimsatt 1997). Those who know the function literature might recognize that this as a generalization of Robert Cummins's classic account (Cummins 1975). It is a generalization because Cummins considers only capacities of containing systems as goal states and not whole-organism capacities such as fitness or autopoiesis. Furthermore, Cummins is also one of those authors who take functions not to be real because they are "interest-dependent". ${ }^{7}$ I will criticize this idea below.

Second, I do not claim that this meta-analysis is complete. There is at least another important variable that could be taken into account, namely an organism's environment (Wimsatt 1997). Clearly, the realization of some goal state G usually depends on there being a suitable environment. However, for simplicity I will omit this here because it will play no role in my argument.

\footnotetext{
${ }^{6}$ Wimsatt (1997) argues that only behaviors and processes can be bearers of functions. By contrast, I prefer maximal flexibility as to what can count as a function bearer.

${ }^{7}$ An anonymous referee went as far as to suggest that Searle's argument is just a version of Cummins's argument according to which functions are interest-dependent. The source of this interest-dependence is the fact that, in Cummins's account, the capacity of the containing system may be chosen arbitrarily (for a critique of this view, see Weber 2005). While Searle's argument may be somewhat similar, it offers an additional challenge, namely the eliminativist thesis that I try to in this paper.
} 
The idea of this meta-analysis is that there are different ways in which such a function predicate can be satisfied, depending in particular what kind of goal state $\mathrm{G}$ and system $\mathrm{S}$ are filled in. One possibility consists in taking $\mathrm{S}$ to be an organismic subsystem and the goal state $\mathrm{G}$ in some capacity that this system has, for example ${ }^{8}$ :

$\left(F_{1}\right)$ The heart's $(X)$ function with respect to blood circulation $(G)$ in the cardiovascular system $(\mathrm{S})$ is to pump blood $(\varphi)$.

As this example should make clear, the term "goal state" is not to be taken too literally; I use it just for want of a better term (it sounds less teleological than "goal" simpliciter). In particular, it shouldn't be taken to imply that the goal state must be a static condition. Some goal states are activities themselves, as in the case of blood circulation. Other goal states, such as the ones to be examined below, are not activities but dispositions or capacities, such as fitness or the capacity to survive. Such goal states may come in very different forms. If there is anything they all have in common, perhaps, it is that they must exhibit some kind of stability. Thus, a highly transient or modally fragile property of a system will hardly be a goal state for a functional attribution, but I do not want to insist on this point.

Another possibility for a goal state is to take the whole organism as the relevant system S and some whole-organism capacity such as fitness or the capacity to survive (sometimes dubbed "self-reproduction" or "autopoiesis" which may be translated as "self-production"):

\footnotetext{
${ }^{8} \mathrm{~F}_{1}$ corresponds to Cummins's analysis, which is also known as "causal role functions".
} 
$\left(F_{2}\right)$ The heart's $(\mathrm{X})$ function with respect to fitness/autopoiesis $(\mathrm{G})$ in the mammalian organism (S) is to pump blood $(\varphi)$.

Both $F_{1}$ and $F_{2}$ are legitimate function predicates. ${ }^{9}$ Finally, we may also fill in the placeholders of the abstract function predicate in such a way as to obtain one or another variant of the well-known "etiological" or "selected effect" accounts of functions ${ }^{10}$ :

$\left(F_{3}\right)$ The heart's $(\mathrm{X})$ function in the mammalian organism $(\mathrm{S})$ with respect to fitness

(G) that caused hearts to be selected in the mammal's ancestors is to pump blood $(\varphi)$.

Of course, more needs to and can be said about the satisfaction conditions of such predicates, and/or the truth conditions of predications in which they figure. But before I come to this, I will discuss some general features of the function predicate thusly construed. In particular, I will take on the issue of the ontological objectivity of functions.

\section{Ontological Objectivity of Functions}

In order to address the issue of ontological objectivity, I will proceed as follows. I will first defend a thesis of relativity of function ascriptions with respect to goal states. Then, I will show that this thesis is fully compatible with ontological objectivity of functions.

Consider the following thesis:

\footnotetext{
${ }^{9} \mathrm{~F}_{2}$ roughly corresponds to the account proposed by Bigelow and Pargetter (1987), which is sometimes referred to as "dispositional" or "life chances"-account.

${ }^{10}$ Well-known proponents of this view include Millikan (1989) or Neander (1991).
} 
(R) A function attribution without specification of a goal state has no truth-value.

It should be clear that thesis $\mathrm{R}$ is implicit in the kind of meta-analysis considered in the previous section. If functions are a four-place relation one relatum of which being a goal state, the satisfaction of a function predicate requires necessarily that a goal state be specified. Without such a specification, a function ascription is as just as unsatisfied as "the function of $\mathrm{X}$ is to regulate blood glucose level", which obviously has no truth-value. Of course, the same is true of function ascriptions that lack specification of the values for the other variables. I focus on the goal-state variable because it is most relevant to Searle's ontological claim.

Obviously, the argument just given for $(\mathrm{R})$ presupposes a Cummins-style meta-analysis. However, I think independent evidence for $(\mathrm{R})$ could be cited. Biologists sometimes disagree about the truth-value of function statements even though there is no disagreement in regard of the non-functional facts (for an example, see Germain, Ratti, and Boem 2013). This could be explained by their implicitly assuming different goal states for the function predicate.

That thesis $\mathrm{R}$ is not trivial should be clear from the fact that not all analyses of the function predicate are consistent with it. For example, those authors who believe that there is a unique intrinsic teleological organization in an organism (e.g., Mossio, Saborido and Moreno 2009) will presumably reject it.

In any case, it should be clear that the thesis $\mathrm{R}$ in no way threatens the objectivity of biological functions. If the goal state $\mathrm{G}$ picked out by a function predicate exists, and if the item X's activity to $\varphi$ in S stands in an appropriate relation (to be defined) to the goal state, then the function ascription is true no matter what we do or do not value. The investigator's interests or values do no figure in the function predicate, nor does its satisfaction depend in 
any way on such interests or values. Thus, function ascriptions are perfectly objective, provided that the X's $\varphi$-ing in S can stand in a suitable relation to the goal state $\mathrm{G}$ and this goal state exists. Note also that there is nothing teleological or mysterious about these goals states. ${ }^{11}$ Fitness or the capacity to self reproduce, or also lower-level goal states such as the circulatory system's capacity to pump blood are perfectly natural properties, if there are such things.

The only thing that might depend on the investigator's interest may be the extent in which the truth of a function statement is worth knowing or scientifically significant. Thus, where Searle went wrong was in supposing that if functional truths are only worth knowing if we care about survival or reproduction, then such truths are themselves relative to our interests. But this doesn't follow. Statements can be objectively true without being scientific significant or worth knowing (Kitcher 2001). Function ascriptions are no different in this respect: If no-one valued survival or reproduction, they might not be worth knowing. But this is not the same as their not being true or the functions' not existing. Ontology has nothing to do with scientific significance or with what's worth knowing, it's about what there is.

As it has become clear in this section, the ontological objectivity of functions hinges on the conditions under which a function ascription stating the obtaining of a relation between function bearer, containing system, activity and goal state can be objectively true. To know these conditions, of course, requires that we know what the functional relation itself is. This is the question to which I turn now.

${ }^{11}$ There is no presumption here that organisms are in some sense "goal-directed systems" (cf. (Sommerhoff 1950; Nagel 1961), an idea that just clouds the issues in my view. 


\section{On the Core Meaning of Function Predicates}

It is customary today to hold that there is not just one but many concepts of function (see, e.g., Wouters 2003). On this pluralistic view, the many different analyses of the function predicate that have been proposed by philosophers may all have their applications in different biological disciplines. For example, the etiological analysis of function (Neander 1991; Millikan 1989; Griffiths 1993; Godfrey Smith 1994; Garson 2016) may capture the way in which functions are ascribed in evolutionary biology, while causal role functions (Cummins 1975) may be more what neuroscientists are interested in (Craver 2001). Of course, there may also be several conceptions of function in use within the same biological discipline (a point emphasized by Garson 2016). However, I contend that these different conceptions of function differ only in referring to different goal states (and sometimes different systems) while the core meaning of the functional predicate is always the same. The meta-analysis proposed in Section 2 actually supports this view. But what is this core meaning that is invariant across different analyses of the function predicate? I suggest the following:

For any function predicate $\mathrm{F}:\langle\mathrm{X}, \mathrm{G}, \mathrm{S}, \varphi>: \mathrm{F}$ is satisfied iff $\mathrm{S}$ 's having $\mathrm{G}$ depends on X's $\varphi$-ing.

I should emphasize that this analysis is somewhat simplified. As was already mentioned, it leaves out the environment as a potentially relevant variable. Furthermore, the dependence involved must be understood in the right way, namely not in the sense that S's having G de- 
pends on X's $\varphi$-ing alone. We must allow that there are other activities that actually or potentially contribute to G's being realized by S. Furthermore, the account as stated is vulnerable to the problem of functional equivalents. ${ }^{12}$

To motivate this proposal, let us plug some concrete biological items into the predicate. To use a well-trodden example, "the heart's function in the circulatory system is to pump blood" can thus be analyzed as "the circulatory system's capacity to transport oxygen and nutrients depends on the heart's blood-pumping". To use a different goal state, the function statement could also be interpreted as "the inclusive fitness of humans depends on the heart's pumping blood", or "a human being's chance to survive depends on the heart's pumping blood". All these statements are true and are possible meanings of a function ascription. The exact meaning will depend on the context in which the statement is made; as I suggested: the goal state is often implicit.

Even the so-called "etiological account", in its many versions, can be accounted for. All we need to do is to insert as a goal state the ancestors' fitness instead of the fitness of the present organisms. To be more precise, we need to say that fitness in the ancestors depended

\footnotetext{
${ }^{12}$ Thanks to Jos Uffink for pointing this out. The problem of functional equivalents arises because functions can normally be performed by a different item or mechanism. In particular Hempel (1959) and Nagel (1961) considered this to be a difficulty that an account of functional explanation must come to terms with. E.g., the thermic insulation function of bird plumage could be performed by hair, or the kidneys' function can be performed by a dialysis machine. Obviously, when someone is attached to a dialysis machine, his osmoregulation no longer depends on the kidneys, and yet the kidneys still seem to have the function of osmoregulation. I think there are different ways of dealing with this problem (see also Wimsatt 1997) but this problem is beyond the scope of this essay.
} 
on the function bearer's activity in such a way as there was selection for this activity and that this selection process caused present-day organisms to carry the function bearer (Griffiths 1993). (Here, the causal idiom is appropriate, in my view, but see (Walsh 2007). But at the end of the day, even this very rich functional attribution basically states a dependence of a goal state - fitness that caused natural selection - on the function bearer's activity in the relevant type of system. This is what makes me think that the general meta-analysis that I propose can be applied to all kinds of functional attributions.

An obvious question concerns the nature of the dependence relation that defines functional predicates on the present account. For only if this dependence relation is objective can functions themselves be objective. In spite of its crucial importance, the literature on functions is remarkably silent about the nature of this dependence relation. I suggest that there are different candidates that could fit the bill, including in particular: (1) supervenience, (2) causality, (3) part-whole relations, (4) mechanistic constitution, (5) metaphysical grounding. I shall discuss them in turn.

(1) Supervenience: Two sets of properties G and P are said to be supervenient iff indiscernibility with respect to the P-properties entails indiscernibility with respect to the Gproperties. Supervenience has been used to characterize the relationship between mental and physical as well as that between biological and physical properties. A well-known example is fitness. On this view, two organisms that share the same physical properties and the same environment must have the same fitness (Sober 1984). An advantage of fitness is thought to be its compatibility with multiple realizability, which is important to account for biological properties. However, supervenience also has some awkward characteristics. In particular, it is not an explanatory relation (Weber 1996). For this reason, I don't take it to be a contender here, because in whatever specific relation functional dispositions stand to goal states, they must be part of an explanation of why S has G (Cummins 1975). 
(2) Causality: When we consider examples such as the heart's blood pumping it seems clear that some causal relations are involved. What would be more natural to say than that the heart's contractions cause the blood to flow or the blood pressure to increase? I think that examples such as these are bona fide causal relations, but it should be noted that this causal relation is not what defines a function on my account. A functional relation obtains, for example, between the heart's blood pumping, the circulatory system's capacity to transport oxygen and nutrients, and a type of organism. This relation is not easily characterized as causal. The heart's blood pumping does not appear to "cause" the circulatory system to have the capacity of transporting oxygen and nutrients in some organisms (even if it is true that the heart causes blood flow). It rather seems that the blood pumping co-constitutes this capacity, together with the arteries, the veins, the blood itself, etc. Note also that the pumping and the capacity occur at the same time, while causes normally precede their effects. The irrelevance of causality is perhaps even more manifest when we consider the functions generated by goal states such as survival or fitness. It is clearly odd to say that the heart's blood pumping "causes" the organism to have a capacity to reproduce and to survive, even though heart failure may cause nonsurvival or death. It is also odd to say that blood pumping "causes" fitness. What could perhaps make sense is to speak of heart output as a cause of fitness differences. However, here we use a quantitative variable that specifies the "how much" of blood pumping, not the fact of blood pumping itself. Nonetheless, the case of fitness may be special and I cannot do it full justice here (see Weber 1996).

(3) Part-whole relations: Indeed, we have already noticed that constitutive or partwhole relations are often involved in functional relations. It makes perfect sense to say that the heart's blood pumping is a part of the complex activity of circulation, or that the passage of sodium through ion channels is a part of action potentials, etc. At least some functions are 
no different in this respect. However, mereology might not be the right category for all functions. For example, it would not seem right to say that blood pumping is a part of an organism's fitness or of it's capacity to survive. Here, the notion of metaphysical ground might be more appropriate (see below).

(4) Mechanistic constitutive relevance. This notion was developed mainly by Craver (2007) as a part of his account of biological mechanisms. Craver distinguishes etiological explanations that cite a cause of some event or phenomena (for example, the release of neurotransmitters at a chemical synapse caused by influx of calcium ions) from what he calls constitutive explanations. Both kinds of explanations are mechanistic. The latter involves the identification of a set of entities and their activities that constitute a phenomenon or a process. For example, the opening and closing of ion channels in neuronal membranes constitutes the phenomenon of action potential. The relationship between the phenomenon and the entities and activities belonging to the mechanism is construed by Craver as constitutive relevance and is non-causal. Causal relations are diachronic, while constitutive relations are synchronic. Craver defends a criterion of mutual manipulability as a way of detecting such constitutive relations. The relation of constitutive relevance can be easily assimilated in a functional framework. Mechanistic constituents acquire (causal role-) functions by co-constituting a phenomenon, which may itself have a function (Weber 2005).

(5) Metaphysical grounding: The notion of ground has recently drawn a lot of attention in metaphysics (e.g., Schaffer 2009; Fine 2012). The idea is that there exists a form (or several forms) of dependence that is neither identity nor causality nor mere supervenience but a kind of non-causal explanatory relation. Typical examples cited include claims such as: The existence of the singleton set $\{$ Socrates $\}$ is grounded in the existence of Socrates, that "Socrates is pale" is true is grounded in the fact that Socrates is pale, or the fact that Sam feels pain in his right foot is grounded in the fact that some of his nerve fibers are firing. Thus, to say 
that Socrates's being pale grounds the truth of the statement "Socrates is pale" means that Socrates's being pale explains why the statement "Socrates is pale" is true. It is because Socrates is pale that "Socrates is pale" is true. The kind of explanation involved here is clearly not causal. Grounding theorists think it is a genuine form of metaphysical explanation and characterizes also other relations such as the one between mental states and brain states, which is widely thought to be non-reductive and distinct from identity. Grounding is frequently taken to be primitive and further characterized via its formal properties, which include asymmetry, transitivity and irreflexivity. There is also logical grounding, for example, we can say that the truth of 'P' grounds the truth of 'P or Q'. Grounds may be full or partial, i.e., the truth of 'P' partially grounds the truth of ' $\mathrm{P}$ and $\mathrm{Q}$ ' and the truth of ' $\mathrm{P}$ ' and of ' $\mathrm{Q}$ ' together fully ground the truth of 'P and Q'

This combination of features might make grounding an attractive candidate for analyzing functional dependencies. For, as I have argued above, causality doesn't always fit the bill for constituting a functional relation. By contrast, it seems that what function bearers do always provides an explanation (or part of an explanation) for the realization of the goal state, whatever the goal state is. So functions are always explanatory and our account should make sure that they are. To the extent in which grounding relations are explanatory (if they are), they might just have what it takes. ${ }^{13}$

Do we have to commit to any one of these dependence relations? I believe not. Different kinds of functions may involve different dependency relations. A function bearer may contribute to a goal state either by causing this state, or by co-constituting it, or by being part

\footnotetext{
${ }^{13}$ It should be noted that there is no consensus as to how grounding is related to the other dependency relations mentioned here. Thus, my listing grounding as an alternative to the other dependency relations may appear like a category mistake to some.
} 
of it, or by (partially) grounding it. Thus, on this view, a statement attributing a function is disjunctive. This would also be in line with the pluralistic spirit of my account (more about this in Section 5), which is intended to be compatible with all the major analyses of biological functions that have been proposed.

The crucial point for the purposes of this paper is the following: Functional truths are no less objective or no more mind-dependent than any of the relations that can realize them. Of course, antirealist positions can and have been defended about causality, part-whole relations, constitutive relations and grounding. But this is not what antirealists about functions usually do. Like Searle, they tend to take, for example, causality to be something that exists in the world mind-independently and then proceed to question that functions are equally objective. But as I have shown, if functional predicates are properly understood, they are just as objective as any of the other relations discussed above, because functional predicates contain these relations in addition to a goal state.

In the following section, I want to show how my account can help to meet another challenge raised by Searle, namely the question of what a functional description adds to a causal description. Answering this challenge is important to avoid Searle's eliminativist conclusion.

\section{What Does Functional Vocabulary Add to the Causal Vocabulary?}

A part of Searle's challenge to the objectivity of functions consists in the question of what functional vocabulary adds to the causal vocabulary. On his view, what functional ascriptions add to causal explanations is an evaluation, which he takes to be subjective. Therefore, functional ascriptions add nothing objective to a causal account. With respect to the goal of discovering natural facts, thus, functional vocabulary is dispensable and therefore eliminable. In this section, I will try to show contra Searle that functional ascriptions are not eliminable. 
In order to do so, we can appeal to the considerations about the relationship of functional and causal relations already presented. As we have seen in the previous section, a functional relation is typically not a causal relation but rather a relation of either mechanistic constitution, a part-whole relation, or a relation of metaphysical grounding that obtains between a function bearer or its activity and the relevant goal state. However, I do not want to exclude that there are also cases where a relation between a function bearer or its activity and the relevant goal state is causal. In any case, if this is correct, then it is clear that a functional relation can be realized in different ways. Such a relation is always realized by one of the relations discussed (and perhaps there are more), but the function predicate is more general and more abstract than any of these concepts.

Thus, a first answer that can be given to Searle's challenge consists in saying that there is no systematic relationship between functional statements and causal statements. Presumably, he presupposes that functional statements are basically causal statements plus something else, where this extra ingredient is evaluative in nature. But if the two are not systematically related in general, as I contend, this presupposition falls and the challenge loses some of its bite. At least, the challenge must then be re-formulated.

A possible re-formulation is this: What does functional vocabulary add to statements that express the existence of a relation of mechanistic constitution, part-whole, ground, or causality between a function bearer and some goal state, depending on which one of these relations realizes the functional dependence of the goal state on the function bearer? In other words, why don't we just use vocabulary that represents such dependency relations instead of invoking functions? Why is functional vocabulary not eliminable?

Before answering the re-formulated challenge, let us pause to note that the issue of eliminability has also been raised in the context of causality itself. According to causal plural- 
ists, it is a mistake to think that there is a single kind that corresponds to the concept of causation. Most of the classic accounts of causality thought that there is such a kind. For example, it has been argued time and again that causality is just regularity, or counterfactual differencemaking, or probability raising, or mechanism, or transmission of a conserved quantity, and so on. However, as is well known, each of these accounts of causality faces counterexamples where causality seems to be involved yet some proffered criterion for causality is not satisfied, or where some criterion is satisfied but there appears to be no causality involved. Of course, it could be that all these accounts are inadequate and that the correct unified account that covers all and only real cases of causality has just not yet been found. Causal pluralists such as Psillos (2009) prefer a different diagnosis. On their view, the search for a unified account of causality is a fool's errand because, much like the common cold, causality is just a set of symptoms for which there is no single underlying essence that is always responsible for the presence of these symptoms (and not all the symptoms may always be present). In other words, the truth-makers for causal statements are disunified. There is nothing that all the possible truth-makers for a causal statement have in common.

This kind of causal pluralism partly draws on Elisabeth Anscombe's insight that causal talk is such that any specific causal statement could be replaced without any loss by filling in some specific verb for "causes", for example, "push", "scrape", "hurt", "knock over", "squash", etc. Thus, it doesn't add anything to the content of the statement that Billy shattered a window if it is said that Billy caused a window to shatter. It is the specific activity of shattering that makes the causal statement true in this case. In another case of "cause", it might be something that has nothing in common with shattering that makes the causal statement true. Thus, the verb "to cause" is highly abstract; it doesn't have any independent representational content. Its only use is perhaps in expressing some abstract generalizations. 
Psillos terms this view "atheist causal pluralism", however, he insists that it is not a form of antirealism about causality. Causal statements are objective and truth-apt, but they are not representational, i.e., they don't represent anything over and above what can be expressed by using more specific verbs such as "to shatter". Thus, causal statements can be true, but they are not made true by a unified class of truth-makers, i.e., something that belongs to the ontological furniture of the world qua causal relation. However, Psillos does not draw the conclusion that causal vocabulary is eliminable. Quite on the contrary, he contends that it is useful for framing generalizations.

Perhaps a similar story can be told about functional vocabulary. As we have seen, the function predicate is highly flexible. Depending on the context, it can relate quite different kinds of function bearers from molecules to entire organ systems to different goal states. Furthermore, the exact relation it expresses can also vary with context; as we have seen, functional predicates may state either a constitution relation, a part-whole relation, a grounding relation, or a causal relation. The dependence relation between functional activities and goal states is multiply realizable. Functional vocabulary can therefore be used to generalize across very different things. I suggest that it is in part this flexibility that makes the function predicate so useful for biology. Thus, it is not because they value life that biologists attribute functions to things instead of looking only for causal dependencies (or constitutive relations, grounding, etc.). It is because the function predicate plays important epistemic roles. ${ }^{14}$ Furthermore, as I have shown, functional statements are no less objective than causal statements or statements about constitution, mereology, or grounding.

\footnotetext{
${ }^{14}$ It should be noted that functions are not only used for explanatory purposes, they also play an important role in scientific classification (Griffiths 2006).
} 
In the final section, I will consider an important objection to the view that I have defended,

\section{Too Many Functions?}

A frequent objection to the account of the ontology of functions that I have given here is the following: If the goal state of functional ascriptions is considered to be variable in the way I have assumed, does this not lead to an ontological explosion of functions? Assuming that there is no limit to the number of capacities that could serve as goal state for a functional attribution, doesn't such an account of the ontology of functions as I have given here leave us with infinitely many functions?

My response to this challenge consists in simply biting the bullet and accepting that all these functions exist. However, as I have already pointed in in Section 3, the fact that lots of such functions exist does not mean that they are also interesting or scientifically significant. As Philip Kitcher has famously argued, only a tiny fraction of all true statements in any subject domain are also scientifically significant (Kitcher 2001). What makes them significant is strongly dependent on the investigative context. (Objectively) true function statements are no different in this respect: They are legion, but only a few of them are scientifically interesting. Which ones are scientifically interesting strongly depends on the biological sub-discipline and on the specific questions that biologists work on.

I should stress that by acknowledging the context-dependence of the significance of function statements I am not making a concession to Searle or to any others who take functions to be interest- or value-dependent (e.g., Cummins 1975). For all that I am admitting is that the scientific significance of function statements may be interest-dependent, not that their truth or the existence of the corresponding functions is so dependent. It is important to keep questions about scientific significance separate from ontological questions. 


\section{Conclusions}

I have shown that a closer look at the nature of functional predicates renders obsolete such reasons against the objectivity of biological functions as those that have been given by Searle or Cummins. Such arguments rest on the fallacy of inferring from the relativity of functions with respect to some non-unique goal state the mind-dependence of functions. But to the extent in which such goal states (e.g., the capacity to survive or to produce offspring) are mindindependent properties of an organism, statements that state the dependence of that goal state on the activities of some parts of the organism may be objectively true irrespectively of the interests of the investigator.

In order to defend the objectivity of functions, I have used a general meta-analysis of function predicates that I think covers some of the major analyses of biological functions that have been proposed (including selected effect-functions and dispositional or causal role-functions). According to this meta-analysis, all functional claims state at least a quaternary relation between a part of an organism, an activity of that part, a system that contains the part (which may be the entire organism), and a goal state. The goal state may be survival or fitness, or it may be the activity of a sub-system (e.g., the circulatory system). Whether or not a function statement is true/false depends on the relevant relation actually holding/not holding, which is independent of what anybody values or doesn't value. However, the extent in which true functional statements are considered to be scientifically significant obviously is not so independent. Questions about what statements are true and what statements are worth knowing should be strictly separated.

I have proposed that functional statements may incorporate any of the dependence relations of causality, part-whole, mechanistic constitution, or grounding, depending on the specific goal state and the organismic parts that are being considered. Furthermore, I have tried to 
meet Searle's challenge of saying what functional vocabulary adds to the causal vocabulary. Taking into account the different kinds of dependence that may be involved in functional relations, I have slightly reformulated this problem. Then, I have provided reasons for viewing the concept of function as indispensable. I have located these reasons in the multiple realizability and the resulting flexibility of the function concept, which provides an epistemic rationale for functional discourse.

\section{Acknowledgements}

A first version of this paper was written for the $8^{\text {th }}$ Munich-Sydney-Tilburg Conference in Philosophy of Science which took place at the University of Tilburg in June 2015. I wish to thank the organizers and Guest Editors for their support. In addition, the paper has benefited from discussion with audiences at the Minnesota Center for Philosophy of Science, the Department of Philosophy, University of Fribourg, and the $4^{\text {th }}$ European Advanced Seminar in the Philosophy of the Life Sciences at the Konrad Lorenz Institute for Evolution and Cognition Research, Klosterneuburg, September 2016. Special thanks to Lorenzo Casini for critically reading the manuscript. This research was in part funded by the John Templeton Foundation. 


\section{References}

Bigelow, John, and Robert Pargetter (1987), "Functions", Journal of Philosophy 84:181-196.

Boorse, Christopher (1977), "Health as a Theoretical Concept", Philosophy of Science 44:542-573.

Craver, Carl (2007), "Constitutive Explanatory Relevance", Journal of Philosophical Research 32.

Craver, Carl F. (2001), "Role Functions, Mechanisms, and Hierarchy", Philosophy of Science 68 (1):53-74.

Cummins, Robert (1975), "Functional Analysis", Journal of Philosophy 72:741-765.

Fine, Kit (2012), "Guide to Ground", in F. Correia and B. Schnieder (eds.), Metaphysical Grounding: Understanding the Structure of Reality, Cambridge: Cambridge Unviersity Press, 37-80.

Garson, Justin (2016), A Critical Overview of Biological Functions. Berlin: Springer.

Germain, Pierre-Luc, Emanuele Ratti, and Federico Boem (2013), "Junk or Functional DNA? ENCODE and the Function Controversy", Biology and Philosophy 29 (6):807-831.

Godfrey Smith, Peter (1994), "A Modern History Theory of Functions", Noûs 28 (3):44-362.

Griffiths, Paul E. (1993), "Functional-Analysis And Proper Functions", British Journal For The Philosophy of Science 44 (3):409-422.

Griffiths, Paul (2006), "Function, Homology and Character Individuation", Philosophy of Science 73:1-25.

Hempel, Carl G. (1959), "The Logic of Functional Analyses", in L. Gross (ed.), Symposium on Sociological Theory, New York: Harper and Row, 271-301.

Kant, Immanuel (1913), Gesammelte Schriften, Band V. Berlin: Königlich-Preußische Akademie der Wissenschaften. 
Kingma, Elselijn (2016), "Situation-Specific Disease and Dispositional Function", British Journal for the Philosophy of Science 67:391-404.

Kitcher, Philip (2001), Science, Truth, and Democracy. Oxford: Oxford University Press.

Kusch, Martin (2006), A Sceptical Guide to Meaning and Rules: Defending Kripke's Wittgenstein. London: Acumen.

McLaughlin, Peter (2001), What Functions Explain: Functional Explanation and SelfReproducing Systems. Cambridge: Cambridge University Press.

Millikan, R. G. (1989), "In Defense of Proper Functions", Philosophy of Science 56:288-302. Mossio, Matteo, Cristian Saborido, and Alvaro Moreno (2009), "An Organisational Account of Biological Functions", The British Journal for the Philosophy of Science 60 (4):813-841.

Nagel, Ernest (1961), The Structure of Science. Problems in the Logic of Scientific Explanation. London: Routledge and Kegan Paul.

Neander, K. (1991), "Functions As Selected Effects - The Conceptual Analysts Defense", Philosophy Of Science 58 (2):168-184.

Psillos, Stathis (2009), "Causal Pluralism", in R. Vanderbeeken and B. D’Hooghe (eds.), Worldviews, Science and Us: Studies of Analytical Metaphysics. A Selection of Topics From a Methodological Perspective, Singapore: World Scientific, 131-151.

Ratcliffe, Matthew (2000), "The Function of Function", Studies in History and Philosophy of Biological and Biomedical Science 31:113-133.

Schaffer, Jonathan (2009), "On What Grounds What", in D. Chalmers, D. Manley and R. Wasserman (eds.), Metametaphysics, Oxford: Oxford University Press, 347-383. Searle, John (1995), The Construction of Social Reality. New York: Simon \& Schuster. Sober, Elliott (1984), The Nature of Selection. Evolutionary Theory in Philosophical Focus. Cambridge Mass.: MIT Press. 
Sommerhoff, G. (1950), Analytical Biology. Oxford: Oxfird University Press.

Walsh, Denis M. (2007), "The pomp of superfluous causes: The interpretation of evolutionary theory", Philosophy of Science 74 (3):281-303.

Weber, Marcel (1996), "Fitness Made Physical: The Supervenience of Biological Concepts Revisited." Philosophy of Science 63: 411-31.

Weber, Marcel (2005), Philosophy of Experimental Biology. Cambridge: Cambridge University Press.

Wimsatt, William C. (1997), "Functional Organization, Analogy and Inference." In André Ariew, Robert Cummins and Mark Perlman (eds.), Functions: New Essays in the Philosophy of Psychology and Biology, Oxford: Oxford University Press 173-221.

Wouters, Arno (2003), "Four Notions of Biological Function", Studies in History and Philosophy of Biological and Biomedical Sciences 34:633-668.

Wright, Larry (1973), "Functions", Philosophical Review 82:139-168. 